\title{
Apparent Solubility of Natural Products Extracted with Near-Critical Carbon Dioxide
}

\author{
Helena Sovová \\ Institute of Chemical Process Fundamentals of the Academy of Sciences of the Czech Republic, Prague, Czech Republic \\ Email: sovova@icpf.cas.cz
}

Received October 26, 2012; revised November 28, 2012; accepted December 12, 2012

\begin{abstract}
The apparent solubility controls the initial stage of supercritical fluid extraction of natural products, which is most important for the process economics. Based on the literature, data on $\mathrm{CO}_{2}$ apparent solubility of volatile substances from different matrices as leaves, flowers, rhizomes and seeds were collected and compared with their thermodynamic solubility. The adsorption isotherm derived by del Valle and Urrego as a modification of the isotherm proposed by Perrut $e t$ $a l$. is universal enough to interpret these data as well as the apparent solubility of vegetable oils from seeds, for which it was originally proposed. When the apparent solubility of minor extract components in $\mathrm{CO}_{2}$ is compared with their thermodynamic solubility, their fraction in the extracted mixture should be taken into account.
\end{abstract}

Keywords: Supercritical Fluid Extraction; Solubility; Adsorption Isotherm; Vegetable Oils; Volatile Compounds

\section{Introduction}

Supercritical fluid extraction (SFE) is a green separation process yielding products free of any traces of organic solvents and, as such, it is applied to manufacture hops extract, caffeine-free coffee beans, extracts from spices and medicinal plants, and other products. Supercritical solvent of choice for this purpose is carbon dioxide, which is non-flammable, non-explosive, non-toxic, and inert. Another advantage with respect to thermolabile substances is its low critical temperature, $31.2^{\circ} \mathrm{C}$. The range of extraction conditions is sometimes extended below the critical temperature to liquid $\mathrm{CO}_{2}$.

The SFE is carried out in high-pressure equipment at pressures higher than the critical pressure of $\mathrm{CO}_{2}$, which is 7.14 MPa. The investment cost of a plant for SFE is therefore substantially higher than the cost of a plant for conventional extraction with organic solvents.

The $\mathrm{CO}_{2}$ extracts compete in the market with products of conventional extraction and it is not always possible to make the production cost comparable, though the operation cost of SFE is lower. Both extraction conditions (extraction temperature, pressure, solvent flow rate and time of extraction) and pretreatment of extracted plant should be optimized to minimize the production cost. The fluid leaving the extractor under optimum conditions is usually a saturated solution of extract in supercritical $\mathrm{CO}_{2}$, or almost saturated solution [1]. Thus, the concentration of saturated solution in equilibrium with extracted plant, called apparent solubility, is an important quantity con- trolling the extraction kinetics and affecting the production cost.

The term "apparent" is used to distinguish the equilibrium fluid phase concentration established when the plant material to be extracted is contacted with supercritical $\mathrm{CO}_{2}$ for sufficient time from the thermodynamic solubility of extract in the solvent, in the absence of plant matrix. The apparent solubility can be estimated from published data on the kinetics of SFE from different plants, provided that the solvent residence time was sufficient for saturation.

The apparent and thermodynamic solubilities are usually identical for vegetable oils extracted from seeds [2]. The apparent solubility of volatile substances, however, is often much lower than their thermodynamic solubility in $\mathrm{CO}_{2}$. Rodrigues et al. [3] determined the apparent solubility of extracts from three aromatic plants and found that the apparent solubility of clove oil was by one or two orders higher than the apparent solubility of ginger and eucalyptus oils. Sovova et al. [4] made experiments and thermodynamic modeling for a model system representing the partition of volatile substances between $\mathrm{CO}_{2}$ and vegetable oil during their SFE from seeds. Recently, del Valle and Urrego [5] published a study where different aspects of SFE from plants are discussed. With respect to the apparent solubility in $\mathrm{CO}_{2}$, they modified previously published relationships for adsorption isotherms of vegetable oils extracted from seeds and obtained a very good description of experimental data. Further, they proposed a simple and rational explanation for 
the low apparent solubility of volatile compounds: when the initial extract content in the plant is low (as it is usually in the case of volatile compounds), its concentration in $\mathrm{CO}_{2}$ filling the void space in the extraction bed is much lower than its thermodynamic solubility, even if it is all dissolved immediately.

The aim of this work was to collect more literature data on the apparent solubility of $\mathrm{CO}_{2}$ extracts from plants in order to check these hypotheses on the effect of plant matrix on extraction kinetics.

\section{Apparent Solubility of Vegetable Oils from Seeds}

\subsection{Combined Equilibrium Relationship}

Experimental data on SFE kinetics are usually obtained by determining the amount of extract at certain time intervals. Extraction yield, $e$, is calculated as the mass of extract over the mass of plant that was placed into the extractor (the feed). The extraction yield is plotted against the extraction time, $t$, or against the solvent-to-feed ratio, $q$, which is equal to the mass of passed carbon dioxide over the feed. The experimental points are connected by cumulative extraction curve (Figure 1). In the plot $e=e(q)$, the slope of the cumulative curve is equal to the concentration of extract in the solution flowing out of the extractor.

When the plant material is mechanically pretreated by milling, grinding, cutting or other method, a part of soluble substances is released and is freely accessible on the surface of obtained plant particles that form the extraction bed. As supercritical fluids exhibit very good transport properties, the mass transfer from particle surface to bulk fluid is quick. When several minutes of static extraction precede opening the valve at extractor outlet at $t$ $=0$, equilibrium is established and the apparent solubility can be read from the initial slope of cumulative extraction curve. It is, however, necessary to check that the

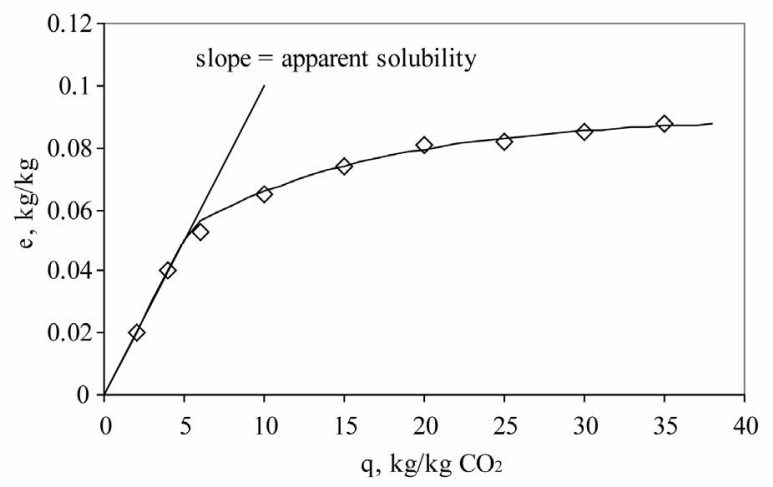

Figure 1. Experimental data and typical cumulative extraction curve. The initial slope equals the apparent solubility for sufficient residence times. solution was saturated. This can be done by evaluating two extraction runs carried out at different solvent residence times, it means at different solvent flow rate-tofeed ratios. If the solution was saturated in both cases, the slopes of the two extraction curves $e=e(q)$ are equal. The content of extractible substances in the plant can be estimated as the asymptote of extraction curve at large times. To obtain from extraction curve more information on kinetic parameters, mathematical models including mass balance of extracted substances in the solid and fluid phases, relationships for mass transfer rates in the particles and in the fluid phase, and a relationship for phase equilibrium are necessary.

It was repeatedly confirmed that the apparent solubility of vegetable oils extracted from seeds with dense $\mathrm{CO}_{2}$ is equal to their thermodynamic solubility in $\mathrm{CO}_{2}$, which is similar for all vegetable oils consisting of triacylglycerols of fatty acids, most of which contain $18 \mathrm{C}$ atoms. As the solubility was correlated with temperature and $\mathrm{CO}_{2}$ density [6-8], the apparent solubility of vegetable oils can be predicted according to these correlations. The fact that plant matrix does not affect the initial extraction rate of oils from seeds is connected with high content of oils in seeds, which is measured in tens of percent. When, however, the initial content of oil in seed was reduced by preceding extraction, the equilibrium apparent solubility of oil from depleted seeds was lower than the thermodynamic solubility and decreased with de- creasing oil content (Figure 2).

The effect of seed matrix on the solubility of sunflower oil in $\mathrm{CO}_{2}$ was observed and modelled by Perrut et al. [10]. The initial slope of extraction curve was equal to the thermodynamic solubility of oil and, after a part of oil was extracted, the extraction continued at a slower rate, with a lower slope of extraction curve. Such a decrease is normally attributed to mass transfer resistance

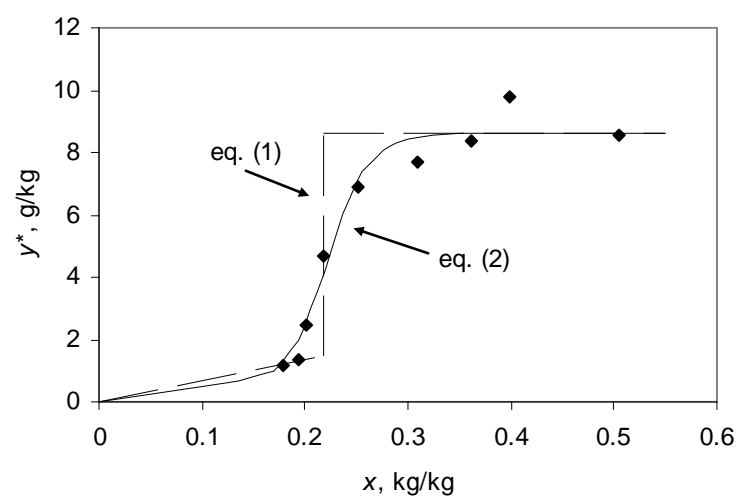

Figure 2. Equilibrium solubility of oil extracted with $\mathrm{CO}_{2}$ at $40^{\circ} \mathrm{C}$ and $35 \mathrm{MPa}$ from canola seeds in dependence on the oil concentration in seeds. The experimental data [9] are redrawn according to ref. [5]. Coefficients of Equation (1): $y_{0}=$ $8.6 \mathrm{~g} / \mathrm{kg}, x_{t}=0.22 \mathrm{~kg} / \mathrm{kg}, K=6.8 \mathrm{~g} / \mathrm{kg}$. Coefficients of Equation (2): $y_{0}=8.6 \mathrm{~g} / \mathrm{kg}, x_{t}=0.23 \mathrm{~kg} / \mathrm{kg}, K=5.0 \mathrm{~g} / \mathrm{kg}, n=12.5$. 
in the seed particles after the easily accessible oil from particle surface has been exhausted. In this case, however, the solution flowing out of the extractor was still saturated because the extraction curves $e=e(q)$ measured for different residence times overlapped after the decrease in extraction rate as well as in their first section. Perrut et al. therefore proposed equilibrium function in the following form:

$$
y^{*}=y_{0} \text { for } x \geq x_{t}, y^{*}=K x \text { for } x \geq x_{t}, K x_{t}<y_{0}
$$

where $y^{*}$ is the equilibrium fluid phase concentration, $y_{0}$ is the thermodynamic solubility, $x$ is the solid phase concentration, $x_{t}$ is the minimum solid phase concentration at which the seed matrix does not affect the apparent solubility, and $K$ is the partition coefficient for oil interacting with seed matrix. Perrut et al. were aware that real equilibrium curve is smooth but simplified it to this form in order to minimize the number of adjustable coefficients. Using Equation (1) in a model for SFE, Sovová [11] derived the condition under which the overall extraction curve does not exhibit the second decreased slope corresponding to the apparent solubility of oil interacting with matrix, though this interaction does exist: the initial concentration of oil in the seed matrix, $x_{0}$, must fulfill the inequality $K x_{0}>y_{0}$.

It is relatively easy to ensure saturation of the solution flowing out of the extractor when a free solute is dissolved. When the solute interacts with matrix, the local driving force of the extraction is lower and much larger residence time is necessary to achieve the saturation. Thus, the apparent solubility read directly from the second slope of extraction curves could be underestimated in the case of solute interacting with matrix, though the initial slope measured for the free solute gives a correct value of solubility, $y_{0}$. To obtain correct value of partition coefficient $K$, solution of a complete model for SFE where both equilibrium and mass transfer relationships are included should be compared with experimental extraction curve.

A smooth variant of the equilibrium function was recently published by del Valle and Urrego [5]:

$$
y^{*}=K x+\frac{x^{n}}{x_{t}^{n}+x^{n}}\left(y_{0}-K x\right)
$$

Equation (2) reduces to Equation (1) for high values of exponent $n$. Numerical integration of SFE model equations is substantially easier when the equilibrium is described by this smooth equilibrium curve instead of the broken curve, Equation (1). Besides, the smooth curve fits well the available equilibrium data (Figure 2).

\subsection{Summary}

Though the thermodynamic solubility of oil in $\mathrm{CO}_{2}$ is usually a sufficient equilibrium characteristic to model the whole extraction curve, it should be borne in mind that after a part of oil has been extracted, the rest is bound to matrix and its equilibrium fluid phase solubility is therefore lower and monotonously decreases in the further course of extraction. Equations (1) and (2) closely describe these changes.

\section{Apparent Solubility of Volatile Substances in $\mathrm{CO}_{2}$}

\subsection{Thermodynamic Solubility of Terpenes, Essential Oils and $\mathrm{CO}_{2}$ Extracts}

The content of volatile substances in plants and herbs is usually a few per cent or less and therefore it is expected that the solute-matrix interaction plays in their SFE a more important role than in the SFE of vegetable oils from seeds. While the vegetable oils are regarded in SFE as one compound because the solubility of individual oil triglycerides in $\mathrm{CO}_{2}$ is similar and therefore no fractionation of extract occurs, the SFE of volatile substances from aromatic plants takes place simultaneously with extraction of non-volatile substances. Different groups of extract components have different solubility and therefore fractionation in time is observed, and both initial composition and asymptotic yield are pressure and temperature dependent. Despite of this, for the sake of simplicity, the extracts will be regarded as one compound in the estimation of apparent solubility.

Similarly to the techniques used to produce essential oils (steam distillation or hydrodistillation, and pressing in the case of citrus oils), the SFE is a separation technique that isolates from plant materials volatile substances, mostly terpenoids: monoterpenes (MT) and oxygenated monoterpenes (OMT), sesquiterpenes (ST) and oxygenated sesquiterpenes (OST). Besides, the extracted oleoresin contains non-volatile substances like fatty oil, cuticular waxes, higher terpenoids, alkaloids and other minor components. The volatiles-to-non-volatiles ratio in the extract is controlled by extraction conditions; the fraction of non-volatile substances increases with increasing extraction time and with increasing pressure.

The differences in thermodynamic solubility of terpenoids, essential oils and $\mathrm{CO}_{2}$ extracts are evident in Figure 3.

Monoterpenes are represented by $\alpha$-pinene, oxygenated monoterpenes by $c i s$-verbenol, and sesquiterpenes by $\alpha$-humulene. The solubility of bergamot oil, where the percentage of MT and OMT is almost equal, is depicted in the plot between the solubilities of the two classes of terpenoids. The following solubilities of $\mathrm{CO}_{2}$ extracts from three plants were measured in the team of Prof. Meireles. Clove oil was extracted with liquid $\mathrm{CO}_{2}$ at $25^{\circ} \mathrm{C}$ and $15 \mathrm{MPa}$ from clove buds, rich in essential oil. Its major components are eugenol, eugenol acetate (both 
OMT) and $\beta$-caryophyllene (ST) and, correspondingly, its solubility in $\mathrm{CO}_{2}$ is slightly lower than the solubility of OMT in Figure 3. Very probably, its solubility is similar to the solubility of essential oil from clove buds. Nevertheless, in contrast to vapor-liquid equilibrium at temperatures $40^{\circ} \mathrm{C}$ and more, the system clove buds extract $+\mathrm{CO}_{2}$ exhibits two liquid phases in equilibrium with a vapor phase at temperatures $30^{\circ} \mathrm{C}$ and $35^{\circ} \mathrm{C}$. The solubility of vetiver grass oil is much lower. Its volatile fraction consists of ST and OST, and though the solubility of OST in $\mathrm{CO}_{2}$ is expected to be lower than that of ST, this difference cannot be large enough to explain the low solubility of the vetiver grass oil. The more probable reason is the presence of cuticular waxes and other non-volatile compounds, all of them less soluble in $\mathrm{CO}_{2}$ than the volatile fraction, as the vetiver grass oil was extracted with supercritical $\mathrm{CO}_{2}$ at $40^{\circ} \mathrm{C}$ and $20 \mathrm{MPa}$, under the conditions where the solubility of cuticular waxes is not negligible. The lowest solubility in $\mathrm{CO}_{2}$ exhibits the fennel extract, extracted from seeds with dense $\mathrm{CO}_{2}$ at $30^{\circ} \mathrm{C}$ and $25 \mathrm{MPa}$, under the conditions when fatty oil is relatively well soluble. Thus, the fraction of fatty oil components in fennel extract is high and strongly affects its solubility in $\mathrm{CO}_{2}$.

\subsection{Desorption from Plant Matrix}

The apparent solubility listed in Table 1 was calculated from the first slope (or, where indicated, from the second slope) of cumulative extraction curves of SFE carried out at $40^{\circ} \mathrm{C}$, published in the literature. Their values at $9-10$ $\mathrm{MPa}$ are much lower than the solubility of free extracts shown in Figure 3 and therefore we assume that these extract are adsorbed on plant matrix, as suggested already by Goto et al. [27].

It is evident in Figure 4 where the data from Table 1

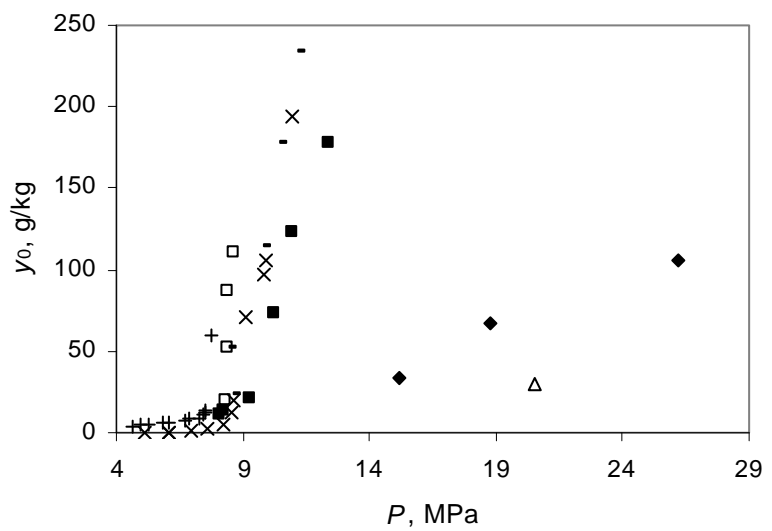

Figure 3. Thermodynamic solubility in $\mathrm{CO}_{2}$ at $40^{\circ} \mathrm{C}$. (+) $\alpha$-pinene [12], ( $\times$ ) cis-verbenol [12], (-) $\alpha$-humulene [13], ( $\square$ ) essential oil: bergamot [14], (ם) $\mathrm{CO}_{2}$ extract: clove buds [15], $(\diamond) \mathrm{CO}_{2}$ extract: vetiver grass [16], $(\triangle) \mathrm{CO}_{2}$ extract: fennel seed [17]. are plotted that no significant increase of apparent solubility with increasing pressure occurs. Thus, the generally recommended low pressures (9-10 MPa) for SFE of volatile substances at $40^{\circ} \mathrm{C}$ are substantiated not only because the coextraction of less soluble compounds is reduced but also because the kinetics would not be markedly enhanced at higher pressures.

Similar apparent solubilities were evaluated from literature data at $50^{\circ} \mathrm{C}$ (not shown here).

\subsection{Washing Out of Free Solute}

All extraction curves were checked for the phenomenon described in detail by del Valle and Urrego [5] and in-

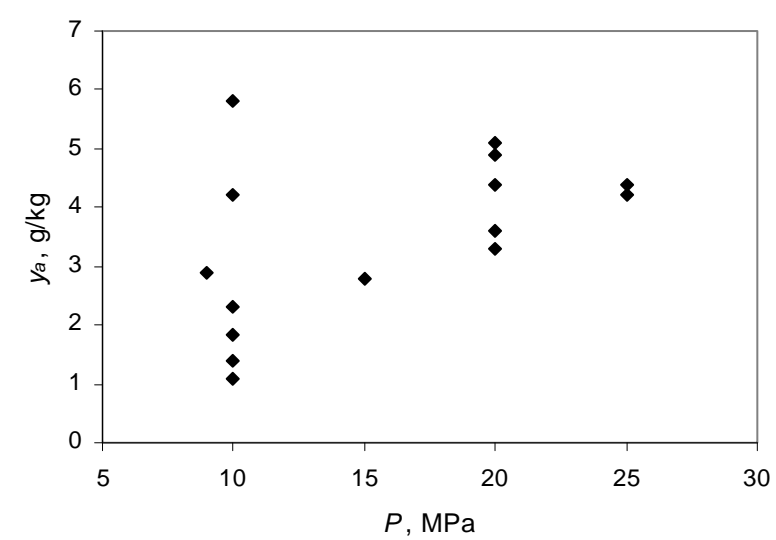

Figure 4. Apparent solubility of extracts adsorbed on plant matrix, reported in Table 1.

Table 1. Apparent solubility $\left(y_{a}\right)$ of volatiles extracted from plants with $\mathrm{CO}_{2}$ at $40^{\circ} \mathrm{C}$.

\begin{tabular}{|c|c|c|c|c|}
\hline Plant & Substrate & Pressure, $\mathrm{MPa}$ & $y_{a}, \mathrm{~g} / \mathrm{kg}$ & Ref. \\
\hline Chamomile & flowers & 10 & 1.8 & [18] \\
\hline Chamomile & flowers & 20 & 5.1 & {$[18]$} \\
\hline Chamomile & flowers & 10 & 1.1 & [19] \\
\hline Chamomile & flowers & 25 & 4.4 & [19] \\
\hline Clove $^{\mathrm{a}}$ & buds & 10 & 2.3 & [20] \\
\hline $\begin{array}{c}\text { Cordia } \\
\text { verbenacea }\end{array}$ & leaves & 20 & 3.3 & {$[21]$} \\
\hline Ginger & rhizome & 15 & 2.8 & [22] \\
\hline Ginger & rhizome & 25 & 4.2 & {$[22]$} \\
\hline Orange $^{a}$ & peel & 20 & 3.6 & [23] \\
\hline Orange $^{a}$ & peel & 20 & 4.4 & [23] \\
\hline Peppermint & leaves & 10 & 1.4 & {$[24]$} \\
\hline Peppermint & leaves & 9 & 2.9 & {$[25]$} \\
\hline Peppermint & leaves & 10 & 5.8 & {$[25]$} \\
\hline St. John's Wort & aerial part & 10 & 4.2 & {$[26]$} \\
\hline St. John's Wort & aerial part & 20 & 4.9 & [26] \\
\hline
\end{tabular}

${ }^{\mathrm{a}}$ Second slope. 
cluded in the model for SFE [11] as "Case C", when all free solute dissolves in the solvent before the solvent starts flowing out of the extractor and then it is quickly washed out. It occurs when the content of free solute in the plant is not sufficient to saturate the solution. The cumulative extraction curve should show a break to slower extraction of the solute bound to matrix at the time equal to the residence time. When the mass of plant in the extractor is $N$, the mass of the solvent in the void space is $M$, the mass flow rate is $F$ and the content of free solute on the surface of plant particles is $x_{1}$, the initial fluid phase concentration will be $y_{a}=x_{1} N / M$, the residence time is $t_{r}=M / F$ and the corresponding solvent-tofeed ratio is $q_{1}=M / N$.

All extraction curves on which the data in Table 1 are based were inspected for the early break at $t_{\mathrm{r}}$ or $q_{1}$, which was observed for the substrates with the highest contents of volatile substances: clove buds [20] containing $15 \%$ of extract, which apparent solubility in $\mathrm{CO}_{2}$ according to the first slope was $180 \mathrm{mg} / \mathrm{g}$, and orange peels of two sorts, one with $11.1 \%$ orange oil and $y_{a}=40 \mathrm{mg} / \mathrm{g}$ and the other one with $5.5 \%$ orange oil and $y_{a}=30 \mathrm{mg} / \mathrm{g}$ [23]. All other plants contained less than 5\% extract.

\subsection{Partition between Fatty Oil and $\mathrm{CO}_{2}$}

The apparent solubility of volatile substances extracted from seeds should be considered separately because they are distributed between the vapor phase and oil in the seeds, which is insoluble at lower pressures and is coextracted at higher pressures. The apparent solubility of volatile substances from seeds at $40^{\circ} \mathrm{C}$ and $8-12 \mathrm{MPa}$ was shown to be directly proportional to the volatile oilto-fatty oil ratio in the seed and to increase with increaseing pressure [28]. As Figure 5 shows, the apparent solubility evaluated from the first slopes of extraction curves of fennel and nutmeg oils follows this trend.

\subsection{Summary}

The apparent solubility of mixtures of volatile substances is lower than their thermodynamic solubility in $\mathrm{CO}_{2}$. One

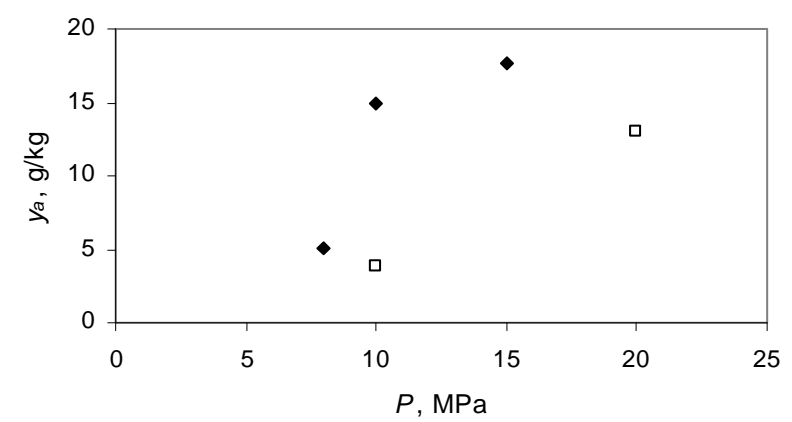

Figure 5. Apparent solubility of extracts from seeds in $\mathrm{CO}_{2}$ at $40^{\circ} \mathrm{C}$ : $(\diamond)$ fennel seed [29], $(\square)$ nutmeg [30]. reason for it is the effect of coextracted non-volatile substances and the other reason is the interaction of extracted substances with plant matrix. Only when the content of volatile substances in the plant is high, as in clove buds and citrus fruit peels, a part of extract is freely washed out.

\section{Extraction Behavior of Minor Extract Components}

\subsection{Apparent Partition Coefficient}

Extracts from botanical materials are always mixtures of compounds but as long as the major components are of similar solubility, the extracted oleoresin is treated as one substance in the analysis of extraction kinetics. When, however, kinetics of SFE of a minor component is examined and the apparent solubility of this compound is compared with its thermodynamic solubility in $\mathrm{CO}_{2}$, large discrepancies are observed, particularly when its content in the plant is by orders of magnitude lower than the content of oleoresin. Such discrepancies were listed by del Valle and Urrego [5] in a table comparing the apparent and thermodynamic solubilities of different carotenoids extracted from tomato skin, carrots, red pepper, and annatto seeds, purine alkaloids from maté tea leaves, and other examples. As Saldana et al. [31] concluded, pure-component solubility data do not enable a direct prediction of extraction kinetics of these substances from natural products.

The apparent solubility of minor components should be considered in respect to their content in the mixture extracted from the herb or plant. Thus, when the content of oleoresin in the plant is initially $x_{o l}$ and the content of the minor component, a part of the oleoresin, is $x_{m}$, the apparent solubility calculated from the first slope of cumulative extraction curve for the minor component should be multiplied by $x_{o l} / x_{m}$ before it is compared with thermodynamic solubility measured for pure substance. Such procedure was applied by Shen et al. [32] who determined the apparent solubility of major and minor components of oleoresin extracted with $\mathrm{CO}_{2}$ from rice bran and used for the corrected quantities term "apparent partition coefficients".

The conversion of apparent solubility to apparent partition coefficient is illustrated in Table 2 on the values measured for maté tea leaves [31]. The contents of extractible minor components caffeine, theobromine and theophylline in the leaves were $4.3,0.35$ and $0.047 \mathrm{mg}$ per $\mathrm{g}$ of dry maté leaves, respectively, and the oleoresin content in dry leaves is estimated by us according to another paper on SFE of maté leaves [33] to $20 \mathrm{mg} / \mathrm{g}$. The apparent partition coefficient of caffeine is still lower than its thermodynamic solubility but the other two purine alkaloids exhibit higher apparent partition coeffi- 
cients than is their thermodynamic solubility, indicating entrainer effects of co-extracted substances.

The second set of literature data used to compare the apparent partition coefficient with thermodynamic solubility concerns the SFE of capsaicinoids from Jalapeno pepper (Capsicum annuum) [34]. The results are shown in Table 3. The contents of oleoresin and capsaicinoids in dry jalapeno pepper were 102.2 and $0.24 \mathrm{mg} / \mathrm{g}$, respectively. The high value of apparent partition coefficient indicates that the extracted oil acts as entrainer of capsaicinoids.

\subsection{Summary}

It should be taken into account in the analysis of SFE kinetics of individual extract components that the solvent capacity is partially occupied by the other mixture components and therefore the apparent partition coefficient should be used instead of the apparent solubility.

\section{Conclusions}

The equilibrium relationship expressing behavior of both free solute and solute interacting with matrix, published by Perrut et al. [9] and modified by del Valle and Urrego [5], was confirmed to be applicable to different solutes and different plant matrixes.

The apparent solubility of vegetable oils extracted from seeds is usually equal to their thermodynamic solubility. The apparent solubility of volatile fraction of extracted oleoresin is lower than its thermodynamic solubility due to the co-extracted non-volatile substances and due to the interaction with matrix (adsorption on the leaf, flower, bud, peel or rhizome matrices and absorption in the fatty oil in seeds). When the content of volatile-rich

Table 2. Apparent partition coefficients in SFE of maté tea leaves at $25.5 \mathrm{MPa}$ and $70^{\circ} \mathrm{C}[5,31]$.

\begin{tabular}{ccccc}
\hline Solute & $\begin{array}{c}\text { Thermodynamic } \\
\text { solubility, g/kg }\end{array}$ & $\begin{array}{c}\text { Apparent } \\
\text { solubility, g/kg }\end{array}$ & $x_{o l} / x_{m}$ & $\begin{array}{c}\text { Apparent } \\
\text { partition } \\
\text { coefficient, } \\
\mathrm{g} / \mathrm{kg}\end{array}$ \\
\hline Caffeine & 2.05 & 0.094 & 4.7 & 0.44 \\
Theobromine & 0.007 & 0.0044 & 57.1 & 0.25 \\
Theophylline & 0.014 & 0.00013 & 426 & 0.55 \\
\hline
\end{tabular}

Table 3. Apparent partition coefficients of capsaicinoids extracted with $\mathrm{CO}_{2}$ from jalapeno pepper [34].

\begin{tabular}{ccccc}
\hline$P, \mathrm{MPa} / T,{ }^{\circ} \mathrm{C}$ & $\begin{array}{c}\text { Thermodynamic } \\
\text { solubility, mg/g solubility, g/kg }\end{array}$ & $\begin{array}{c}\text { Apparent } \\
\text { sol } / x_{m}\end{array}$ & $\begin{array}{c}\text { Apparent } \\
\text { partition } \\
\text { coefficient, } \mathrm{g} / \mathrm{kg}\end{array}$ \\
\hline $12 / 40$ & $0.52^{\mathrm{a}}$ & 0.008 & 426 & 3.41 \\
$32 / 40$ & $2.11^{\mathrm{b}}$ & 0.036 & 426 & 15.3 \\
\hline
\end{tabular}

${ }^{\mathrm{a}}$ Data from ref. [35]; ${ }^{\mathrm{b}}$ Extrapolated from ref. [35]. extract in peels or buds was higher than $5 \%$, washing out of a free part of extract was observed.

The solubility of minor extract components, when considered separately, is better characterized by the apparent partition coefficients than by the apparent solubility. To calculate the partition coefficients, global yield should be determined in addition to the yield of target minor components.

\section{Acknowledgements}

The financial support of the Technology Agency of the Czech Republic (project TA01010578) is acknowledged.

\section{REFERENCES}

[1] P. T. V. Rosa and M. A. A. Meireles, "Rapid Estimation of the Manufacturing Cost of Extracts Obtained by Supercritical Fluid Extraction," Journal of Food Engineering, Vol. 67, No. 1-2, 2005, pp. 235-240. doi:10.1016/j.jfoodeng.2004.05.064

[2] H. Sovová, J. Kučera and J. Jež, "Rate of the Vegetable Oil Extraction with Supercritical $\mathrm{CO}_{2}$-II. Extraction of Grape Oil," Chemical Engineering Science, Vol. 49, No. 3, 1994, pp. 415-420. doi:10.1016/0009-2509(94)87013-6

[3] V. M. Rodrigues, E. M. B. D. Sousa, A. R. Monteiro, O. Chiavone-Filho, M. O. M. Marques and M. A. M. Meireles, "Determination of the Solubility of Extracts from Vegetable Raw Material in Pressurized $\mathrm{CO}_{2}$ : A PseudoTernary Mixture Formed by Cellulosic Structure + Solute + Solvent," Journal of Supercritical Fluids, Vol. 22, No. 1, 2002, pp. 21-36. doi:10.1016/S0896-8446(01)00108-5

[4] H. Sovová, R. P. Stateva and A. A. Galushko, "Essential Oils from Seeds: Solubility of Limonene in Supercritical $\mathrm{CO}_{2}$ and How It Is Affected by Fatty Oil," Journal of Supercritical Fluids, Vol. 20, No. 2, 2001, pp. 113-129. doi:10.1016/S0896-8446(01)00059-6

[5] J. M. del Valle and F. A. Urrego, "Free Solute Content and Solute-Matrix Interactions Affect Apparent Solubility and Apparent Solute Content in Supercritical $\mathrm{CO}_{2}$ Extractions. A Hypothesis Paper," Journal of Supercritical Fluids, Vol. 66, 2012, pp. 157-175. doi:10.1016/j.supflu.2011.10.006

[6] J. M. del Valle and J. M. Aguilera, “An Improved Equation for Predicting the Solubility of Vegetable Oils in Supercritical $\mathrm{CO}_{2}$," Industrial and Engineering Chemistry Research, Vol. 27, No. 8, 1988, pp. 1551-1553. doi:10.1021/ie00080a036

[7] H. Sovová, M. Zarevúcka, M. Vacek and K. Stránský, "Solubility of Two Vegetable Oils in Supercritical $\mathrm{CO}_{2}$," Journal of Supercritical Fluids, Vol. 20, No. 1, 2001, pp. 15-28. doi:10.1016/S0896-8446(01)00057-2

[8] J. M. del Valle, J. C. de la Fuente and E. Uquiche, "A Refined Equation for Predicting the Solubility of Vegetable Oils in High-Pressure $\mathrm{CO}_{2}$," Journal of Supercritical Fluids, Vol. 67, 2012, pp. 60-70. doi:10.1016/j.supflu.2012.02.004 
[9] N. Bulley, M. Fattori, A. Meisen and L. Moyls, "Supercritical Fluid Extraction of Vegetable Oil Seeds," Journal of the American Oil Chemists' Society, Vol. 61, No. 8, 1984, pp. 1362-1365.

[10] M. Perrut, J. Y. Clavier, M. Poletto and E. Reverchon, "Mathematical Modeling of Sunflower Seed Extraction by Supercritical $\mathrm{CO}_{2}$," Industrial and Engineering Chemistry Research, Vol. 36, No. 2, 1997, pp. 430-435. doi:10.1021/ie960354s

[11] H. Sovová, "Mathematical Model for Supercritical Fluid Extraction of Natural Products and Extraction Curve Evaluation," Journal of Supercritical Fluids, Vol. 33, No. 1, 2005, pp. 35-52. doi:10.1016/j.supflu.2004.03.005

[12] M. Richter and H. Sovová, "The Solubility of Two Monoterpenes in Supercritical Carbon Dioxide," Fluid Phase Equilibria, Vol. 85, 1993, pp. 285-300. doi:10.1016/0378-3812(93)80020-N

[13] E. M. Z. Michielin, S. R. Rosso, E. Franceschi, G. R. Borges, M. L. Corazza, J. V. Oliveira and S. R. S. Ferreira, "High-Pressure Phase Equilibrium Data for Systems with Carbon Dioxide, $\alpha$-Humulene and Trans-Caryophyllene," Journal of Chemical Thermodynamics, Vol. 41, No. 1, 2009, pp. 130-137. doi:10.1016/j.jct.2008.07.006

[14] E. Franceschi, M. B. Grings, C. D. Frizzo, J. V. Oliveira and C. Dariva, "Phase Behavior of Lemon and Bergamot Peel Oils in Supercritical $\mathrm{CO}_{2}$," Fluid Phase Equilibria, Vol. 226, 2004, pp. 1-8. doi:10.1016/j.fluid.2004.06.041

[15] A. T. Souza, M. L. Corazza, L. Cardozo-Filho, R. Guirardello and M. A. A. Meireles, "Phase Equilibrium Measurements for the System Clove (Eugenia caryophyllus) Oil $+\mathrm{CO}_{2}$," Journal of Chemical Engineering Data, Vol. 49, No. 2, 2004, pp. 352-356. doi:10.1021/je034190f

[16] T. M. Takeuchi, P. F. Leal, R. Favareto, L. Cardozo-Filho, M. L. Corazza, P. T. V. Rosa and M. A. A. Meireles, "Study of the Phase Equilibrium Formed inside the Flash Tank Used at the Separation Step of a Supercritical Fluid Extraction Unit," Journal of Supercritical Fluids, Vol. 43, No. 3, 2008, pp. 447-459. doi:10.1016/j.supflu.2007.08.002

[17] L. S. Moura, M. L. Corazza, L. Cardozo-Filho and M. A. A. Meireles, "Phase Equilibrium Measurements for the System Fennel (Foeniculum vulgare) Extract $+\mathrm{CO}_{2}$," Journal of Chemical Engineering Data, Vol. 50, No. 5, 2005, pp. 1657-1661. doi:10.1021/je050119t

[18] N. P. Povh, M. O. M. Marques and M. A. A. Meireles, "Supercritical $\mathrm{CO}_{2}$ Extraction of Essential Oil and Oleoresin from Chamomile (Chamomilla recutita [L.] Rauschert)," Journal of Supercritical Fluids, Vol. 21, No. 3, 2001, pp. 245-256. doi:10.1016/S0896-8446(01)00096-1

[19] P. Kotnik, M. Škerget and Ž. Knez, "Supercritical Fluid Extraction of Chamomile Flower Heads: Comparison with Conventional Extraction, Kinetics and Scale-U," Journal of Supercritical Fluids, Vol. 43, No. 2, 2007, pp. 192-198. doi:10.1016/j.supflu.2007.02.005

[20] J. M. Prado, G. H. C. Prado and M. A. A. Meireles, "Scale-up Study of Supercritical Fluid Extraction Process for Clove and Sugarcane Residue," Journal of Supercritical Fluids, Vol. 56, No. 3, 2011, pp. 231-237. doi:10.1016/j.supflu.2010.10.036
[21] S. Quispe-Condori, M. A. Foglio, P. T. V. Rosa and M. A. A. Meireles, "Obtaining $\beta$-Caryophyllene from Cordia verbenacea de Candolle by Supercritical Fluid Extraction," Journal of Supercritical Fluids, Vol. 46, No. 1, 2008, pp. 27-32. doi:10.1016/j.supflu.2008.02.015

[22] J. Martínez, A. R. Monteiro, P. T. V. Rosa, M. O. M. Marques and M. A. A. Meireles, "Multicomponent Model to Describe Extraction of Ginger Oleoresin with Supercritical Carbon Dioxide," Industrial and Engineering Chemistry Research, Vol. 42, No. 5, 2003, pp. 1057-1063. doi:10.1021/ie020694f

[23] A. Berna, A. Tárrega, M. Blasco and S. Subirats, "Supercritical $\mathrm{CO}_{2}$ Extraction of Essential Oil from Orange Peel; Effect of the Height of the Bed," Journal of Supercritical Fluids, Vol. 18, No. 3, 2000, pp. 227-237. doi:10.1016/S0896-8446(00)00082-6

[24] B. C. Roy, M. Goto, A. Kodama and T. Hirose, "Supercritical $\mathrm{CO}_{2}$ Extraction of Essential Oils and Cuticular Waxes from Peppermint Leaves," Journal of Chemical Technology and Biotechnology, Vol. 67, No. 1, 1996, pp. 21-26.

doi:10.1002/(SICI)1097-4660(199609)67:1<21::AID-JCT B522>3.0.CO;2-0

[25] S. Aleksovski, H. Sovova, F. A. Poposka, S. Kulevanova and M. Ristic, "Comparison of Essential Oils Obtained from Mentha pipperita L. Using Supercritical Carbon Dioxide Extraction and Hydrodistillation," Acta Pharmaceutica, Vol. 49, No. 1, 1999, pp. 51-57.

[26] T. Hatami, S. B. Glisic and A. M. Orlovic, "Modelling and Optimization of Supercritical $\mathrm{CO}_{2}$ Extraction of St. John's Wort (Hypericum perforatum L.) Using Genetic Algorithm," Journal of Supercritical Fluids, Vol. 62, 2012, pp. 102-108. doi:10.1016/j.supflu.2011.12.001

[27] M. Goto, M. Sato and T. Hirose, "Extraction of Peppermint Oil by Supercritical Carbon Dioxide," Journal of Chemical Engineering (Japan), Vol. 26, No. 4, 1993, pp. 401-407. doi:10.1252/jcej.26.401

[28] H. Sovová, R. P. Stateva and A. A. Galushko, "Essential Oils from Seeds: Solubility of Limonene in Supercritical $\mathrm{CO}_{2}$ and How It Is Affected by Fatty Oil," Journal of Supercritical Fluids, Vol. 20, No. 2, 2001, pp. 113-129. doi:10.1016/S0896-8446(01)00059-6

[29] B. Damjanović, Ž. Lepojević, V. Živković and A. Tolić, "Extraction of Fennel (Foeniculum vulgare Mill.) Seeds with Supercritical $\mathrm{CO}_{2}$ : Comparison with Hydrodistillation," Food Chemistry, Vol. 92, No. 1, 2005, pp. 143-149. doi:10.1016/i.foodchem.2004.07.019

[30] S. Machmudah, A. Sulaswatty, M. Sasaki, M. Goto and T. Hirose, "Supercritical $\mathrm{CO}_{2}$ Extraction of Nutmeg Oil: Experiments and Modeling," Journal of Supercritical Fluids, Vol. 39, No. 1, 2006, pp. 30-39. doi:10.1016/j.supflu.2006.01.007

[31] M. D. A. Saldana, R. S. Mohamed, M. G. Baer and P. Mazzafera, "Extraction of Purine Alkaloids from Maté (Ilex paraguariensis) Using Supercritical $\mathrm{CO}_{2}$," Journal of Agricultural and Food Chemistry, Vol. 47, No. 9, 1999, pp. 3804-3808. doi:10.1021/jf981369z

[32] Z. Shen, M. V. Palmer, S. S. T. Ting and R. J. Fairclough, "Pilot Scale Extraction of Rice Bran Oil with Dense Car- 
bon Dioxide," Journal of Agricultural and Food Chemistry, Vol. 44, No. 10, 1996, pp. 3033-3009. doi:10.1021/jf950761z

[33] M. C. Esmelindro, G. Toniazzo, D. Lopes, D. Oliveira and C. Dariva, "Effects of Processing Conditions on the Chemical Distribution of Mate Tea Leaves Extracts Obtained from $\mathrm{CO}_{2}$ Extraction at High Pressures," Journal of Food Engineering, Vol. 70, No. 4, 2005, pp. 588-592. doi:10.1016/i.jfoodeng.2004.07.024

[34] J. M. del Valle, M. Jiménez and J. C. de la Fuente, "Ex- traction Kinetics of Pre-Pelletized Jalapeno Peppers with Supercritical $\mathrm{CO}_{2}$," Journal of Supercritical Fluids, Vol. 25, No. 1, 2003, pp. 33-44. doi:10.1016/S0896-8446(02)00090-6

[35] O. Elizalde-Solis and L. A. Galicia-Luna, "New Apparatus for Solubility Measurements of Solids in Carbon Dioxide," Industrial and Engineering Chemistry Research, Vol. 50, No. 1, 2011, pp. 207-212. doi:10.1021/ie1009537 